Таким образом проанализировав ряд объектов, можно выделить основные принципы пластических и художественных решений:

- Окна. Большое влияние на облик здания являются окна: их количество, форма, расположение и ритм. Также возможны световые фонари или отверстия. Окна могут быть стандартными, панорамными, ромбовидными, изогнутыми и неординарной формы.

- Экологические. Творческим специальностям необходима особая эмоциональная среда, в которой можно не только отдохнуть, но и поработать. Поэтому используют озеленение ограждающих конструкций, внутренние дворы, зеленые крыш.

- Коммуникативно-средовые. Использование связей внутренней и внешней среды с помощью формы зданий, фасадных решений (материалов, окон, озеленения, зеркальных плоскостей). Также используют открытые площадки, используемы крыши.

- Образно-художественные. Использование оригинальной формы зданий, современных материалов, композиционного расположения окон, сочетание цветов и фактур.

Исходя из выше сказанного стоит сделать вывод, что при учете всех принципов характерных при проектировании архитектурно-художественных факультетов, мы получим тот функционально-эстетический объект необходимый для воспитания и формирования всесторонне развитого специалиста в области архитектуры.

$$
* * *
$$

1. Квашнин Н. Н. Формирование универсально проектной модели пространственной среды архитектурнохудожественного вуза. - Архитектон: известия вузов» № 14 - Приложение, Июль 2006.

2. Пименова Е. В., Л. М. Демидова. Современные направления в архитектурном проектировании учебных зданий. Инженерный вестник Дона, №1, 2017.

3. Рябова Е. К. Архитектурное формирование образовательной среду зданий творческих вузов. Диссертация на соискание ученой степени кандидата архитектуры, Екатеринбург, 2012

4. СанПиН 2.2.1/2.1.1.1076-01 "Гигиенические требования к инсоляции и солнцезащите помещений жилых и общественных зданий и территорий" п.2.3

5. Сайт файлового архива студентов «Studfiles». [Электронный ресурс]. - Режим доступа: https://studfiles.net.

\title{
Фадеева Е.В. \\ Зарубежный опыт в формировании горнолыжных курортов и применение его на примере горно-рекреационной территории Приэльбрусья
}

Санкт-Петербургский государственный архитектурно-строительного университет doi:10.18411/lj-31-03-2018-88

(Россия, Санкт-Петербург)

idsp: 000001:lj-31-03-2018-88

\section{Аннотация}

Статья посвящена аспектам градостроительного развития сети горнорекреационных центров обслуживания туристов в одном из рекреационных районов Кавказа. Исследуемая территория расположена в Эльбрусском районе республики Кабардино-Балкария вдоль транспортно-коммуникационной оси Нальчик - Терскол. В публикации кратко представлены аналоги из зарубежного опыта, предложены теоретические модели планировочной организации горно-рекреационных центров в условиях Приэльбрусья.

Ключевые слова: градостроительство, система расселения, рекреация, спорт, туризм.

Туризм является одной из ведущих и наиболее динамично развивающихся отраслей мировой экономики, оказывая огромное влияние на такие ключевые отрасли, как транспорт и связь, строительство, сельское хозяйство, производство товаров 
народного потребления, ускоряя при этом социально-экономическое развитие всего района в целом.

В последние три десятилетия горный туризм развивается очень активно. Привлекательность данного вида отдыха обуславливается тем, что он является активным видом спорта и туризма в зимнее время года.

По последним подсчетам в России насчитывается более 4 млн. горнолыжников и сноубордистов, и более 300 горнолыжных центров.

Развитию горно-рекреационных центров в России способствуют различного типа благоприятные условия в виде элементов природной среды, которые включают в себя разнообразие по высоте и рельефу, а так же территориальному расположению. Благоприятность данной среды для нашей страны заключается в уникальных условиях и адаптационной способности геосистем к антропогенным воздействиям, от которых зависят благоприятные условия жизнедеятельности человека, на различных территориях и широтах нашей страны, что положительно влияет на спорт и горный туризм и обеспечивающий наличие плотного снежного покрова в течении 4-5 месяцев в году, а в некоторых горно-рекреационных центрах и более.

В настоящее время в России происходит множество спортивных событий имеющих большое значение как для страны, так и для всего мира. Чемпионат мира по биатлону в 2011 году, зимние Олимпийские и Параолимпийские игры 2014 года , международные Сурдлимские игры 2015, чемпионат по горнолыжному спорту среди юниоров 2016 года в Сочи, нельзя не отметить что все больше крупных международных соревнований проводятся в нашей стране. Яркий пример возрождение горнорекреационной зоны Красная Поляна и подготовка ее к такому крупному событию как зимние Олимпийские игры 2014 года, дало огромный толчок для функционального развития района, это конфигурация сообщений инфраструктур по зонам и экологоградостроительный режим использования территорий в каждой из них, что дало огромный приток туристов, которым теперь не обязательно ехать за границу, чтобы отдохнуть на горнолыжном курорте мирового уровня. Но Красная Поляна не единственное место для отдыха и спорта в горах России, так же известны такие курорты, как Дамбай, Шерегеш, Кировск, Приэльбрусье.

Актуальность, предлагаемой темы, обусловлена необходимостью поиска теоретическо-функциональной модели градостроительного освоения территории для целей развития зимних и летних видов отдыха и туризма. Разработать подобную модель предлагается на примере территории «Приэльбрусья». Исследуемая территория, расположена в Кабардино-Балкарской республике, в западной части Эльбрусского района, вдоль транспортной оси, ограниченной с юга Главным Кавказским хребтом, с востока горой Эльбрус, с севера Боковым Кавказским хребтом, с северо-востока долиной реки Баксан.

Исследуемая территория включает Национальный Природный парк федерального значения - «Приэльбрусье», расположенные вдоль единственной на этой территории планировочной оси - посёлки Терскол, Байдаево, Тегенекли, Эльбрус, Нейтрино, Верхний Баксан и город Тырныауз - административный центр (рис.1).

Территорию отличают характерные условия: сложный рельеф местности в сочетании с бальнеологическими ресурсами, благоприятный для рекреационной деятельности климат, а также наличие самой высокой горной вершины России и Европы - горы Эльбрус, что привлекает поток туристов и спортсменов не только из России, а также из зарубежных стран. Район Приэльбрусья занимает одну из лидирующих позиций по числу проводимых спортивных соревнований в области горнолыжного спорта, сноуборда, альпинизма, скайраннинга, количество которых с каждым годом возрастает.

Вследствие этого здесь ведётся активное строительство учреждений для размещения и обслуживания туристов в районах «Азау» и «Чегет», создавая 
транспортную и антропогенную перегруженность, что приводит к формированию плотной урбанизированной среды и ведёт к утрате целостности природного ландшафта. Несмотря на новое строительство, в отношении Приэльбрусья по-прежнему не создан единый градостроительный план развития. Точечное строительство новых объектов обслуживания туристов противоречит комплексному подходу к освоению территории [1].

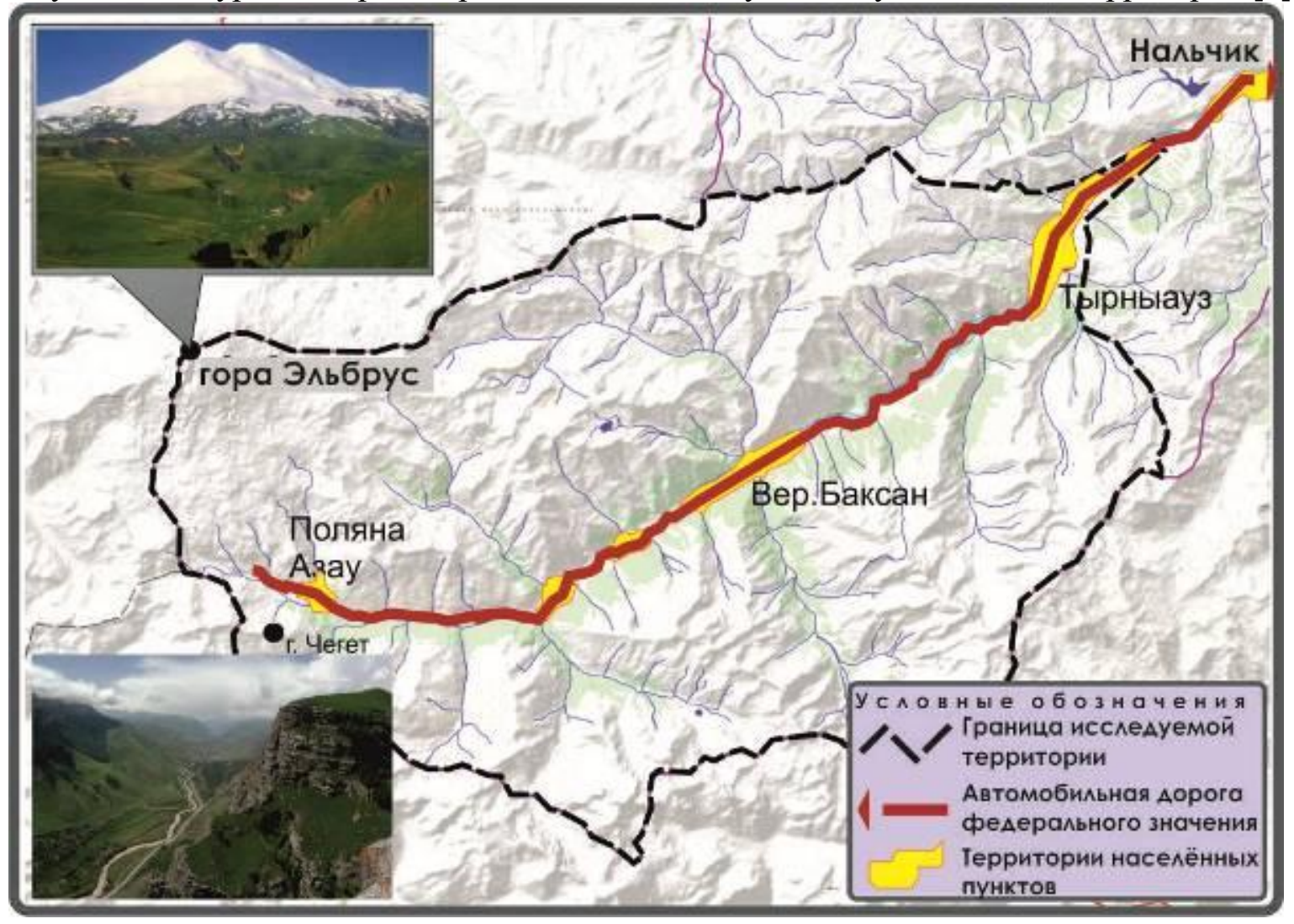

Рис. 1. Расположение грании исследуемой территории

Развитие сверхприбыльной индустрии зимнего отдыха предусматривает строительство современных горно-рекреационных центров и организацию массового отдыха туристов, предоставление им сервисного обслуживания максимально высокого уровня.

Для горнолыжных курортов большое значение имеет развитие туристической инфраструктуры: строительство гостиничных комплексов разного уровня комфортности, организация системы маятниковых, канатно-кресельных и буксировочных дорог, включающей подъемники, трассы, спуски разной протяженности и сложности, учебные склоны, службу трасс и контрольно-спасательную службу, спортивные организации и сооружения, магазины, пункты проката спортивного инвентаря, горнолыжные школы.

В целях поиска направления градостроительного развития системы горнорекреационных центров был рассмотрен практический зарубежный опыт создания аналогичных комплексов в условиях гор. Для этого были выделены наиболее близкие по характеру климатических и геологических условий примеры зарубежных курортов Церматт(Швейцария)[2], Куршевель (Франция) [3], Уистлер(Канада). Критериями выбора аналогов для изучения послужили социальный, ландшафтный и инфраструктурный критерий. [4][5]

Социальный критерий обусловлен близкими транспортными и хозяйственными связями с другими курортам и населенными пунктами, как необходимость обеспечить соответствующую среду для жизни и работы обслуживающей группы и широкий спектр рекреационных занятий для туристов, спортсменов и отдыхающих. Согласно этому критерию выбран Горнолыжный курорт Уистлер (Канада) в провинции Британская 
Колумбия охватывает площадь 3307 га и расположен на высоте 675 м над уровнем моря на расстоянии 126 километров от Ванкувера (137 км от аэропорта Ванкувера). Курорт расположен в системе населённого пункта Уистлер - центром по предоставлению услуг для гостей и жителей. Два горных склона (гор Уистлер и Блэккомб) оборудованы двадцатью четырьмя подъёмниками для горнолыжного спорта. Дно горной долины используется для застройки отелями, ресторанами и барами, а также шале и домами для отдыхающих.

Ландшафтный критерий влияет на композиционно-планировочное построение курорта, а также определяет направление территориального развития курорта на долгий срок в сложных условиях горных ландшафтов. Согласно этому критерию был выбран курорт Церматт (Швейцария) у подножия горы Маттерхорн. При этом форма геологического строении долины, в сочетании с уникальными ландшафтами альпийских гор обуславливают планировочное развитие курорта в линейном направлении. Курорт полностью закрыт для автомобильного движения, разрешены лишь электрические миниавтомобили, коляски запряженные лошадьми. Характерной особенностью этого горного курорта является сохранение и активное использование особенностей местного этнографического жилища с одновременным строительством современных 3-х и 4-х этажных отелей и гостиниц высокого уровня комфорта[6].

Инфраструктурный критерий обусловлен многоуровневой системой горных центров с интенсивной концентрацией функций, плотной сетью транспортных, пешеходных связей и канатных дорог. Этому критерию соответствует Курорт Куршевель (Франция), в основе которого лежит применение системы группового расположения рекреационных центров, сгруппированных в пространстве одной горной долины и объединенных между собой коммуникационными и транспортными связями. Особенностью этого курорта являются сохранение целостности природной и градостроительной среды[7].

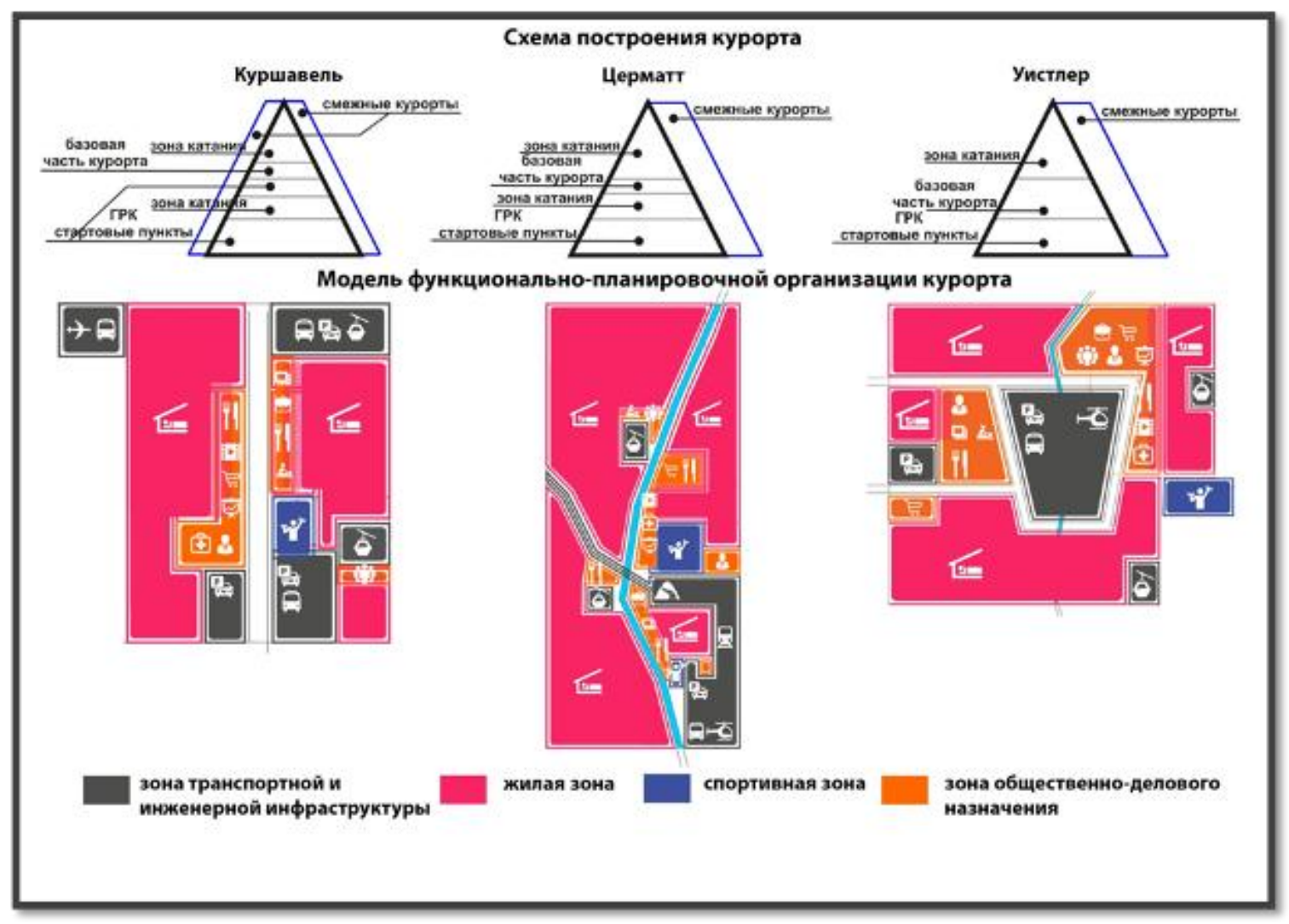

Рис. 2. Теоретические модели, выявленные на основе опыта создания и развития горных курортов 
Большинство рассмотренных авторам горных курортов имеет пирамидальное построение. В нижней части ущелья расположена базовая часть курорта, а именно общественная, жилая зона и транспортный узел. Чаще всего в основе лежат уже существующие населенные пункты. Внизу располагается горно-рекреационный центр и стартовые пункты подъемников, которые сходятся в нескольких вершинных центрах. В стороне, на соседних склонах может находиться похожая по структуре система подъемников. Они объединяются общей областью катания. С помощью сети подъемников туристы имеют возможность перехода из одной горной долины в другую.

Горно-рекреационные центры включают спортивные сооружения, здания общественно-делового назначения, службы эксплуатации подъемников и систем искусственного снегообразования, службы подготовки трасс, контрольно-спасательные службы, пункты проката спортивного инвентаря, горнолыжные школы, пункты приема приезжих и распределения их по курорту (трансферные службы). Функциональный состав горно-рекреационного центра включает объекты обслуживания: рестораны, бары и другие предприятия общественного питания, увеселительные заведения, предлагающие программы отдыха, а также гостиничный комплекс (рис. 2). курортов:

Выделены некоторые принципы планировочного построения территории

1. линейно развитие нескольких рекреационных центров вдоль транспортной оси;

2. центрическое или компактное размещение рекреационных центров;

3. повторение геометрической формы планировочных элементов (кварталов, жилых групп) сложившейся застройки малых городов и деревень в планировочном решении всего курорта;

4. в сложных инженерно-геологических условиях гор интенсивное использование ограниченной площади территории пригодной для застройки, с созданием насыщенной многофункциональной рекреационной среды.

В отношении каждого рассмотренного примера развития территории курорта выделены достоинства и недостатки. Центрическая (компактная) композиция (Уистлер и Церматт) при достижении экономического эффекта за счёт территориальной централизации системы обслуживания и объектов транспортной инфраструктуры, имеет трудности в обслуживании селитебной территории на периферии и ограничивает возможности территориального развития горно-рекреационного центра. Линейная композиция (Куршевель) с дисперсным размещением объектов обслуживания усложняет организацию пешеходных связей.

Исходя из этого опыта, в отношении территорий Приэльбрусья, выявленных в результате многофакторной оценки, предлагаются три модели развития горнорекреационных центров (рис. 5).

Первая модель «двухчастного центрального узла» (предлагается для разработки на территории города Тырныауз, в связи с наиболее подходящей планировочной структурой территории, возможностями ее развития и реновации) удобна схождением системы транспортных и пешеходных связей в центральной части горно-рекреационного центра. В центральном пространстве концентрируются объекты транспортной инфраструктуры: автостанции, парковки, вертолетные площадки. Эти объекты расположены на достаточном удалении от селитебной территории - места проживания туристов, зоны гостиничных комплексов, сгруппированных вокруг зоны общественного назначения (пункты питания и проката, павильоны для культурно-массовых мероприятий). Такое композиционно-планировочное решение имеет небольшие минусы, связанные с наличием вторичных пешеходных связей, воль которых практически отсутствует рекреационная деятельность и часто пустующая периферия курорта. 
Вторая предлагаемая модель «градостроительной сетки» (наиболее подходит для территории поселка Верхний Баксан) подразумевает территории гостиничных комплексов непосредственно в ткани существующего населённого пункта. При этом возникает трудность построения горно-рекреационного центра с учетом существующей транспортной сети и существующей застройки, то есть внедрение в сложившееся пространство. Однако, похожая модель широко применяется в Европе. Форма сетки предполагает много преимуществ, а именно привычная форма построения схожая с городской средой, создание множества узлов для формирования общественных пространств, большее количество маршрутов внутри рекреационного центра. Единственный недостаток данной модели обусловлен длиной пешеходных связей, проходящих через центральное ядро, чем в концепции «Двухчастного центрального узла», где путь практически прямой.

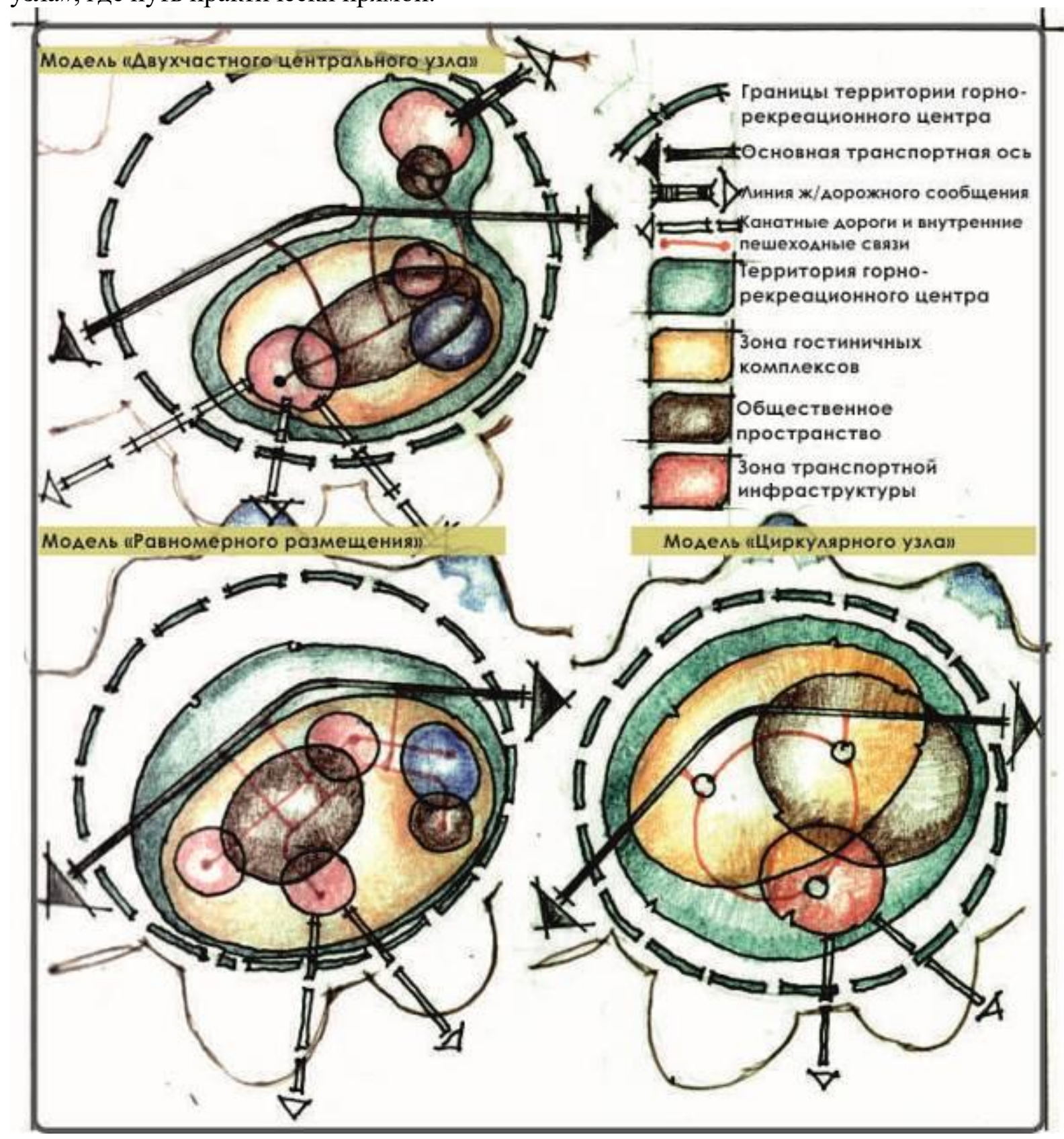

Рис. 3. Предлагаемые теоретические модели концепџий планировочной организаџии горно-рекреаџионных центров в Приэльбрусье 
Третья предлагаемая модель «Циркулярного узла» (предлагается для территории курорта Поляна Азау) характерна формированием центрального пространства как основного ядра курорта. Подобное планировочное решение позволяет осуществлять движение не только через территорию, но и вокруг основных функциональных зон. Недостатком данной концепции является то, что основной узел расположен в центре курорта и не примыкает к склонам и посетители вынуждены пересекать всю территорию курорта, следуя к склонам гор - месту катания на лыжах.

Все три модели, несмотря на выявленные недостатки, применимы к специфическим условиям Кавказских гор, распределяя и направляя потоки туристов и обеспечивая развитие рекреационной деятельности в этом регионе (рис.3).

Четкое понимание концепции формирования центрального рекреационного узла для той или иной территории позволит более грамотно развивать данную территорию, с учетом особенностей рельефа и существующей инфраструктуры, при этом затраты на дальнейшее развитие горно-рекреационного центра возможно уменьшить учитывая существующие транспортные и социальные ресурсы на выбранной территории.

$$
\text { *** }
$$

1. "Разработка схемы территориального планирования Эльбрусского муниципального района КабардиноБалкарской Республики" Н. С. Зайцева Е. А. Задорожная , В. А. Никитин , О. В. Этезова// ФКЗ "Земля" 2012.- 156c.

2. Claudio A. Lauber A. Soft-Movement-Trail Zermatt Bergbahnen AG. Anlagenkonzeptionfüreinan den zukünftigenTourismustrendsorientiertes, umwelt- und naturschonendesOutdoorbewegungsangebot. 2014.

3. Творческое объединение PerekatyPoleКуршевель: немного истории и архитектуры" : http://perekatypole.com

4. Супруненко Ю.П., Горы зовут...: Горно-рекреационное природопользование// Рос.акад. наук. Ин-т географии. - М.: 2003.- 366c.

5. Батчаева Ф.М. "Анализ развития горнолыжного туризма в России" СГАУ. 2013.

6. Ecosign, Mountain Resort Planners Ltd. Zermatt: http://www.ecosign.com/project/zermatt-ru

7. Максимов О.Г., Ополовникова Е.А. Горно-рекреационные комплексы // архитектору-проектировщику, M.: 1981.- 120c.

\section{Шлёнов В.А.}

\section{Проблемы сохранения жилых комплексов авангарда 1920-1930 гг. в Москве}

doi:10.18411/lj-31-03-2018-89

idsp: 000001:lj-31-03-2018-89

\section{Аннотация}

В работе рассматривается аспект уникальности жилых комплексов 1920-30х гг. Основные качества их пространственной организации. А также описываются сложности, возникающие при попытке сохранения этих сооружений.

Ключевые слова: пространственная организация, авангард, конструктивизм, жилые комплексы, Москва

\section{Abstract}

The paper considers the aspect of the uniqueness of residential complexes of the 1920s1930s. The main qualities of their spatial organization. And also describes the difficulties that arise when trying to preserve these structures.

Moscow

Keywords: spatial organization, avant-garde, constructivism, residential complexes,

На сегодняшний день город Москва богат памятниками архитектуры. На момент 2017 года Москву даже признали археологическим памятником. Однако, в силу ряда причин постройки конструктивистов редко признаются памятниками. На данный момент 